\title{
Serendipita indica modulates expression of arginine metabolism genes during colonization of Arabidopsis thaliana roots
}

\author{
Shahbaz Anwar ${ }^{1,2^{*}}$ and Krzysztof Wieczorek ${ }^{1}$ \\ 1. Division of Plant Protection, Department of Crop Sciences, University of Natural Resources and Life Sciences, \\ Konrad Lorenz-Strasse 24, 3430 Tulln-Austria \\ 2. Botany Department, Government Postgraduate College, Sahiwal-Pakistan \\ *Corresponding author's email: shahbazanwarch@hotmail.com
}

Citation

Shahbaz Anwar and Krzysztof Wieczorek. Serendipita indica modulates expression of arginine metabolism genes during colonization of Arabidopsis thaliana roots. Pure and Applied Biology. Vol. 8, Issue 1, pp442-451. http://dx.doi.org/10.19045/bspab.2018.700203

\begin{tabular}{llll}
\hline \hline Received: 07/09/2018 & Revised: 29/11/2018 & Accepted: 01/12/2018 & Online First: 12/12/2018 \\
\hline \hline
\end{tabular}

\section{Abstract}

Endophytic fungus Serendipita indica belongs to the order Sebacinales. It is an extremely versatile root endophyte colonizing more than 150 different plant species including the model plant Arabidopsis thaliana. Colonization of $S$. indica triggers enhanced growth, early flowering, increase in seed content, alteration of secondary metabolite pathways and adaption to different biotic and abiotic stresses. This is why this fungus got ample attention by the plant researchers. In this study, we report modulation in expression of argininosuccinate synthase (AS), argininosuccinate lyase $(A L)$ and arginase $2(A R G A H 2)$ genes in A. thaliana as a result of $S$. indica colonization. Similarly, expression of GUS reporter gene driven by $A S$ and $A R G A H 2$ promoters in roots was altered. $A S, A L$ and $A R G A H 2$ genes were down-regulated at early stage of root colonization i.e at 3 days post inoculation (dpi), with a subsequent up-regulation at later stages (7 and $14 \mathrm{dpi}$ ). Other arginine catabolism genes, Arginine decarboxylase-1 (ADC1), Arginine decarboxylase-2 (ADC2) and Pyrroline-5-carboxylate reductase (P5CR) were strongly upregulated at later stages of $S$. indica colonization. Our findings show significant changes in expression of several important genes in arginine metabolic pathway upon $S$. indica colonization. These changes are very specific and strongly depend on the colonization phase of the fungus.

Keywords: $A L$; $A R G A H 1 ; A R G A H 2 ; A S$; Arginine metabolism; GUS; Quantitative RT-PCR; Serendipita indica

\section{Introduction}

Abiotic and biotic stresses are the major causes of crop losses throughout the world. They primarily include unfavorable climate conditions, different plant diseases and plant pests. One commonly used solution to cope with these stresses is the high chemical input to increase the plant production [1]. However, these soil and plants treatments cause severe damage to environment. Use of biological agents instead of chemical treatments is therefore gaining more attention and importance. Mycorrhizae are already established as beneficial associations of fungi with plants increasing their growth and production. Moreover, endophytic arbuscular mycorrhizal fungi (AMF) are proven to enhance abiotic stress tolerance. These fungi 
have mutualistic relationships with $80 \%$ plant species worldwide [2]. In addition, many AMF associations were shown to be effective against soil born plant pathogens $[3,4]$ and play an important role in nutrient acquisition of host plants [5].

Endophytic fungus Serendipita indica (previously known as Piriformospora indica) belongs to the order Sebacinales. It colonizes roots, grows inter- and intracellularly, and forms spores in the roots as well as on the root surface. Its colonization on A. thaliana roots can be divided into four different phases: (1) extracellular (approx. $1 \mathrm{dpi}$ ); (2) biotrophic (less than 3 dpi); (3) cell death associated (approx. $7 \mathrm{dpi}$ ) and (4) fungal reproduction (approx. 14 dpi), whereupon external and intracellular sporulation occurs approx. at 7 and 14 dpi, respectively [6]. Sebacinales got much attention due to its role in enhancement of plant growth and development [7]. S. indica is also reported to confer stress tolerance against heavy metals, drought, acidity and enhanced resistance against plant pathogens. It has been demonstrated that it is beneficial during the attack of different plant pathogens [8].

Recently the role of arginine metabolism in plant-microbe interactions gained more attention $[9,10]$. In general, arginine pathway is involved in different plant defense responses where it antagonizes pathogens by enhancing nitric oxide production [11]. In plants, arginine is produced from argininosuccinate via argininosuccinate lyase $(A L)$. Argininosuccinate is synthetized from citrulline by the enzyme argininosuccinate synthase $(A S)$. Further, arginine is catabolized by arginase (ARGAHI \& $A R G A H 2)$ to ornithine, which is a precursor for the production of proline via many steps. The final reaction is catalyzed by pyrroline5-carboxylate reductase (P5CR). Arginine is also catabolized to polyamines in many reactions, where the first step involves the synthesis of agmatine by the action of arginine decarboxylase $(A D C 1 \& A D C 2)$.

We are still lacking knowledge on involvement of arginine metabolic pathway during colonization of plants by endophytic fungi. Since $S$. indica induces different modifications in host roots, this study is aimed to elucidate different parts of this pathway during colonization process. Therefore, our work aims at studying the involvement of arginine pathway in $A$. thaliana, $S$. indica interaction. Our findings showed clear modulation of arginine metabolic pathway upon $S$. indica colonization. GUS reporter analysis and gene expression analysis reveals down-regulation of $A S, A L$ and $A R G A H 2$ genes at early stages of colonization with subsequent upregulation at later stages. Expression of catabolic gene was also found significantly increased at later stages of fungus development.

\section{Materials and methods Plant growth and inoculation}

A. thaliana surface-sterilized seeds were grown on $0.2 \%$ Knop medium at $16 \mathrm{~h} \mathrm{light/8}$ $\mathrm{h}$ dark and $25^{\circ} \mathrm{C}$. Potato dextrose agar (Fluka, Germany) was used to culture $S$. indica at $28^{\circ} \mathrm{C}$ in the dark. Inoculation of 12-day-old A. thaliana plants was done by adding potato dextrose agar plugs $(5 \mathrm{~mm})$ containing $S$. indica hyphae $1 \mathrm{~cm}$ away from the roots. Empty plugs were used in control plates.

Plasmid construction and transformation of A. thaliana

GUS promoter line (pAS::GUS) was constructed as described in [9]. Briefly, a 418 bp fragment upstream to start codon of the argininosuccinate synthase gene (At4g24830) was amplified from genomic DNA of A. thaliana. SgsI/AscI and HindIII restriction sites were introduced in the fragment by the specific primer sequences. The PCR products were cloned into binary vector pMDC139 $[12,13]$. Presence of the promoter was confirmed by sequencing of 
the resulted plasmid. Floral dip technique [14] was used for Agrobacterium-mediated plant transformation to insert the binary vectors in A. thaliana (Col-0). Screening of transformed seeds was done by antibiotic selection. Homozygous T3 (Third generation) seeds of lines $\mathrm{p} A S:$ :GUS [9] and pARGAH2::GUS [15] were collected after segregation analysis and used for final characterization of expression patterns.

\section{Histochemical GUS assay}

Histochemical GUS expression was performed using X-GLUC (5-bromo-4 chloro-3-indolyl $\beta$-D-glucuronic acid) (Biomol, Germany). Three, 7 and 14 days post inoculation (dpi) petri dishes containing inoculated plants were opened and X-GLUC solution was added. Dishes were then vacuum-infiltrated for $3 \mathrm{~min}$ and incubated at $37^{\circ} \mathrm{C}$ for eight hours. After incubation, dishes were washed with $70 \%$ ethanol and observed under dissection microscope for GUS staining. Photographs were taken with Axiovert 200M (Zeiss, Austria) using an Axiocam digital camera (Zeiss, Austria).

Sample collection, RNA isolation and quantitative RT-PCR
Root segments were harvested at 3, 7 and 14 dpi from colonized and uncolonized (control) plants of the same age omitting root tips. Samples were immediately shock-frozen in liquid nitrogen. Three plates were used for harvesting at each time point representing one biological replicate. Three biological replicates from independently grown batches were collected for RNA isolation. All experiments were repeated three times. RNA was extracted as described in [9].

Quantitative RT-PCR was performed using an ABI PRISM 7300 Sequence Detector (Applied BioSystems; USA). The PCR was carried out at $50^{\circ} \mathrm{C}$ for $2 \mathrm{~min}, 95^{\circ} \mathrm{C}$ for $5 \mathrm{~min}$ followed by 40 cycles at $95^{\circ} \mathrm{C}$ for $15 \mathrm{~s}, 60^{\circ} \mathrm{C}$ for $30 \mathrm{~s}$ and $72^{\circ} \mathrm{C}$ for $1 \mathrm{~min}$. Primer sequences are listed in (Table 1). 18S RNA primers were used as internal reference. Fold changes were calculated using $2^{-\mathrm{ddCt}}$ method [16]. RNA samples were used from three independent biological replicates. Each biological replicate was run in a set of three technical replicates to minimize the experimental errors.

Table 1. Presents the sequences of the primers used for qRT-PCR. AS, Argininosuccinate synthase; $A L$, Argininosuccinate Lyase; $A R G A H 1$, Arginase 1; $A R G A H 2$, Arginase 2; $A D C 1$, Arginine decarboxylase-1; ADC2, Arginine decarboxylase-2; P5CR, Pyrroline-5-carboxylate reductase

\begin{tabular}{|c|c|c|c|}
\hline Locus & Gene & Direction & Primer Sequence 5' - 3' \\
\hline \multirow{2}{*}{ At4G24830 } & \multirow{2}{*}{$A S$} & Forward & AAAGCACGGGATTGGGCGGA \\
\hline & & Reverse & GCGGATCAAACCATCTTCCTGCG \\
\hline \multirow{2}{*}{ At2G10920 } & \multirow{2}{*}{$A L$} & Forward & GCAGCTCGAACGTGATGCTGGT \\
\hline & & Reverse & CCTCGGAAGCCCACAGTACCCA \\
\hline \multirow{2}{*}{ At4G08900 } & \multirow{2}{*}{$A R G A H 1$} & Forward & AGCTTGGAGGGCCTGTGGAC \\
\hline & & Reverse & GCCTTGTTCCCGTCCTTCCTGG \\
\hline \multirow{2}{*}{ At4G08870 } & \multirow{2}{*}{$A R G A H 2$} & Forward & GGAAGGTGGCTATGCGCGGC \\
\hline & & Reverse & ACACTCCGTGCGCGAATCCC \\
\hline \multirow{2}{*}{ At2G16500 } & \multirow{2}{*}{$A D C 1$} & Forward & GACCCGTGCTGTGATGGGCC \\
\hline & & Reverse & CCGCTGCGGTGAGAGCGTTT \\
\hline \multirow{2}{*}{ At4G34710 } & \multirow{2}{*}{$A D C 2$} & Forward & GCTCGATCAAAGGCCCGGGG \\
\hline & & Reverse & CGCTCTGGGAGACCCGGACA \\
\hline \multirow{2}{*}{ At5G14800 } & \multirow{2}{*}{$P 5 C R$} & Forward & AGCCTTGGCACAGGAGCAACG \\
\hline & & Reverse & GCTCCAAGAACGGTCTGTGAAG \\
\hline \multirow[t]{2}{*}{ At3G41768 } & \multirow{2}{*}{$18 S R N A$} & Forward & TGACACGGGGAGGTAGTGACA \\
\hline & & Reverse & AGTCTGGTAATTGGAATGAGTACAATCTAA \\
\hline
\end{tabular}




\section{Statistical analysis}

Gene expression was calculated using $2^{- \text {-ddCt }}$ method. Statistical variations were tested using ANOVA and LSD tests $(\mathrm{p}<0.05)$ using the statistical software package STATGRAPHICS Plus Version 5.0.

\section{Results}

Characterization of promoter::GUS

\section{transgenic lines}

Temporal expression patterns of previously published $\mathrm{p} A S:: \mathrm{GUS}$ and $\mathrm{p} A R G A H 2:: \mathrm{GUS}$ fusion lines were analyzed $[9,15]$. Here, the promoter activity of $A S$ and $A R G A H 2$ was studied in $S$. indica-colonized roots of $A$. thaliana. pAS::GUS lines showed very weak promoter activity at $3 \mathrm{dpi}$ (Figure 1A). In case of pARGAH2::GUS line promoter activity showed the same trend at 3 dpi (Figure 1D). In contrast, at $7 \mathrm{dpi}$ p $A S:$ GUS activity was observed only in vascular bundles (Figure $1 \mathrm{~B}$ ), and in pARGAH2::GUS line GUS staining could be observed scattered all over the roots (Figure 1E). At 14 dpi in pAS::GUS line, strong GUS activity was found in most regions of the analyzed root tissue (Figure $1 \mathrm{C})$. In case of $\mathrm{p} A R G A H 2::$ GUS line strong promoter activity was also found all over the roots (Figure 1F). These findings were confirmed by at least two independent transgenic lines for both of the genes with consistent and reproducible results.

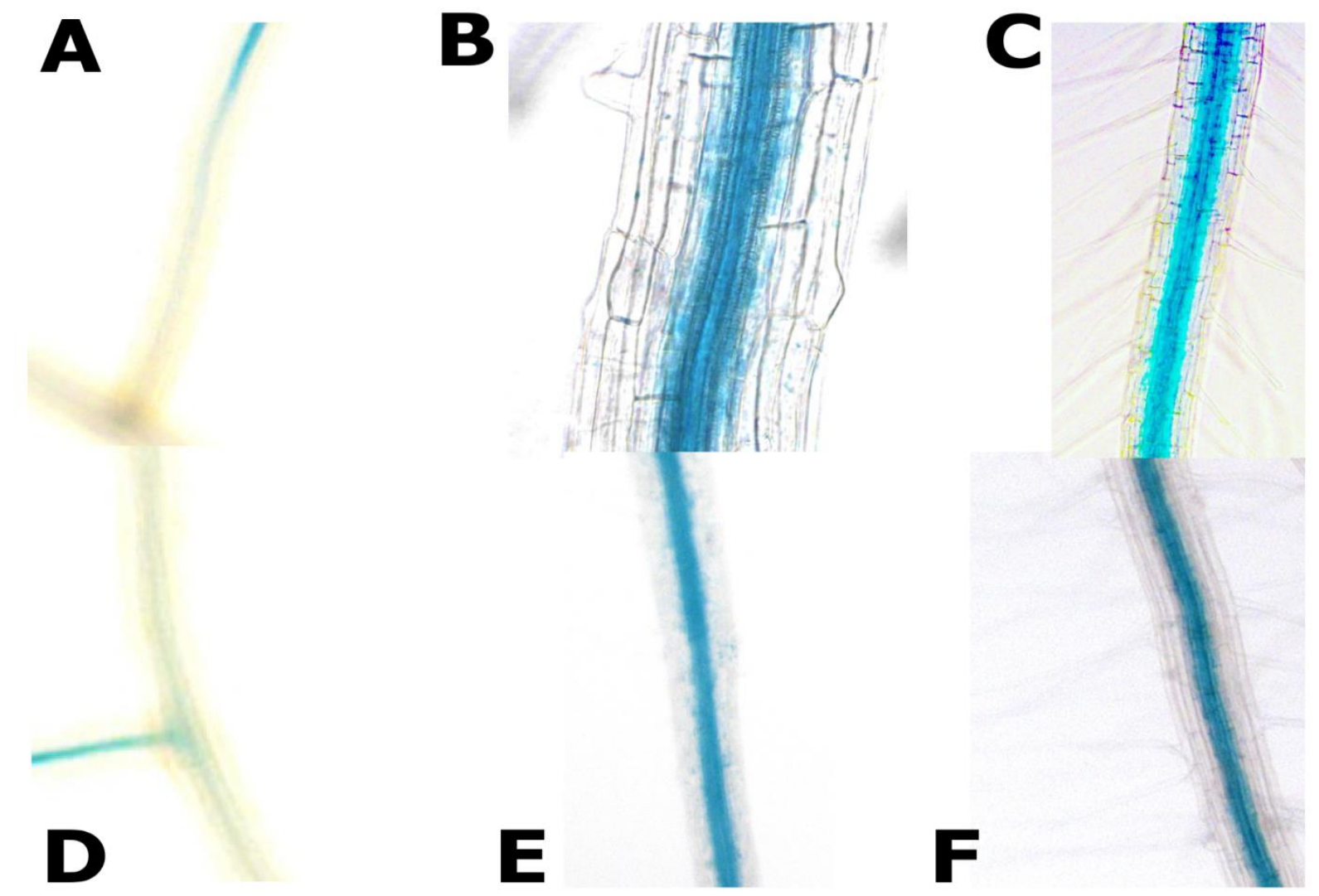

Figure 1. GUS staining upon $S$. indica colonization in roots of pAS::GUS line at A) $3 \mathrm{dpi}$, B) $7 \mathrm{dpi}$, C) $14 \mathrm{dpi}$; and $S$. indica-colonized roots of the pARGAH2::GUS line at D) $3 \mathrm{dpi}$, E) 7 dpi, F) 14 dpi 
Expression analysis of arginine cycle genes Important genes for two anabolic and three catabolic enzymes of arginine metabolic pathway were selected for expression analysis. The entire arginine pathway is presented in (Figure 2). Expression of these genes was analyzed using qRT-PCR at three different time points: early $3 \mathrm{dpi}$, mid $7 \mathrm{dpi}$ and late $14 \mathrm{dpi}$. At an early stage of development (3 dpi), argininosuccinate synthase $(A S)$ showed down-regulation as compared to un-colonized control roots, with a subsequent up-regulation at later time points. However, gene expression was decreased at $14 \mathrm{dpi}$ as compared to $7 \mathrm{dpi}$. Similarly, argininosuccinate lyase $(A L)$ showed the same trend i.e down-regulation at 3dpi and up-regulation at later time points. But in this case gene expression was not as strong as in case of $A S$ (Figure $3 \mathrm{~A} \& \mathrm{~B}$ ). In case of arginase related genes, arginase 1 $(A R G A H 1)$ gene was found up-regulated at all three time points with a strong upregulation at $7 \mathrm{dpi}$ followed by a decreasing trend. Arginase 2 (ARGAH2) showed a significant down-regulation at $3 \mathrm{dpi}$ with almost two-fold up-regulation at later time points (Figure 3C \& D). Among other catabolic genes, i.e. $A D C 1, A D C 2$ and $P 5 C R$, an increasing trend was found at all-time points tested. Strongest up-regulation was found at 14 dpi in all three genes (Figure 3E, $F \& G)$.

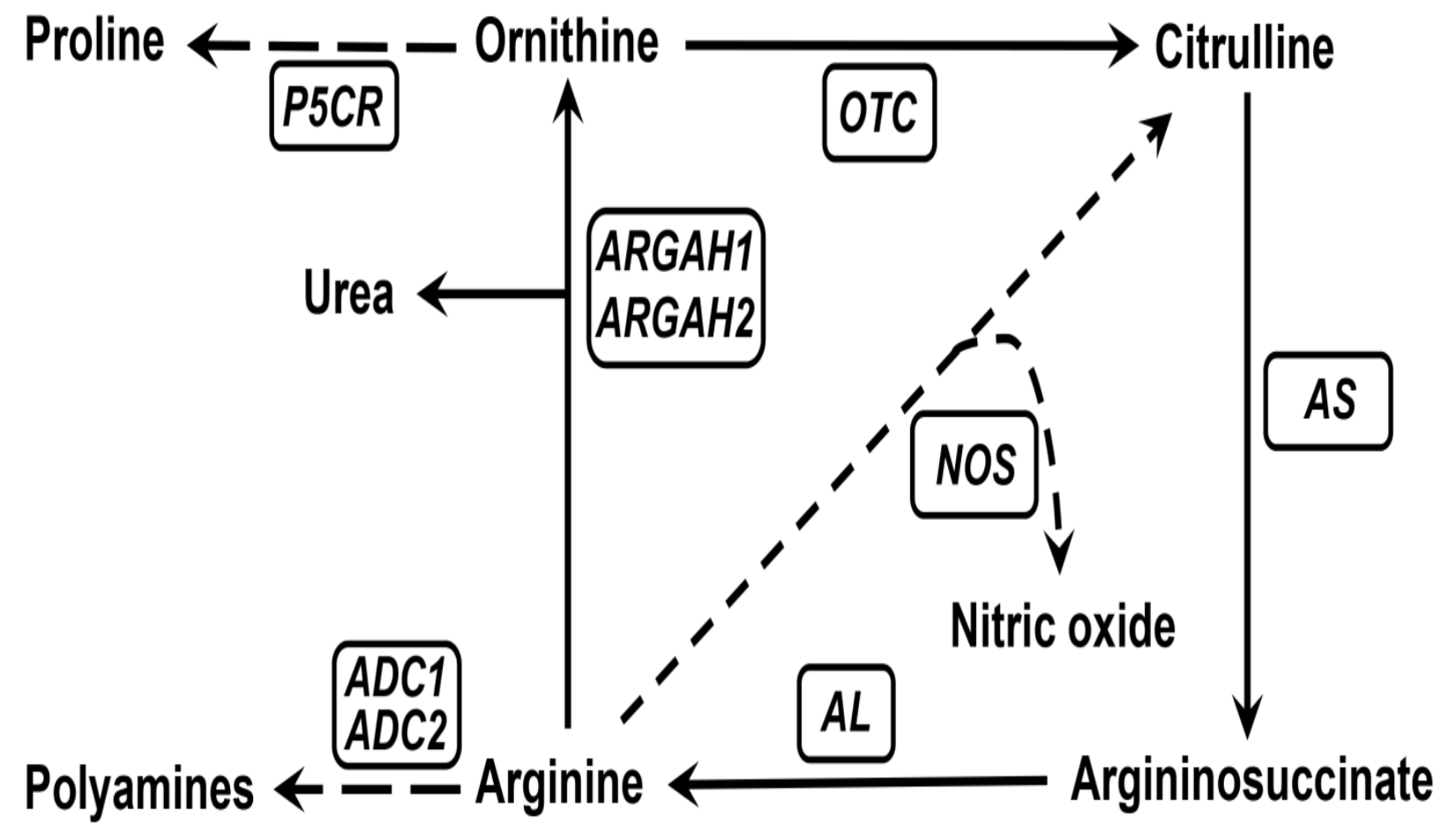

Figure 2. Arginine metabolism in A. thaliana. Important enzymes are shown for each reaction. Dotted arrows indicate more than one reaction (modified from PMN: https://plantcyc.org/) 

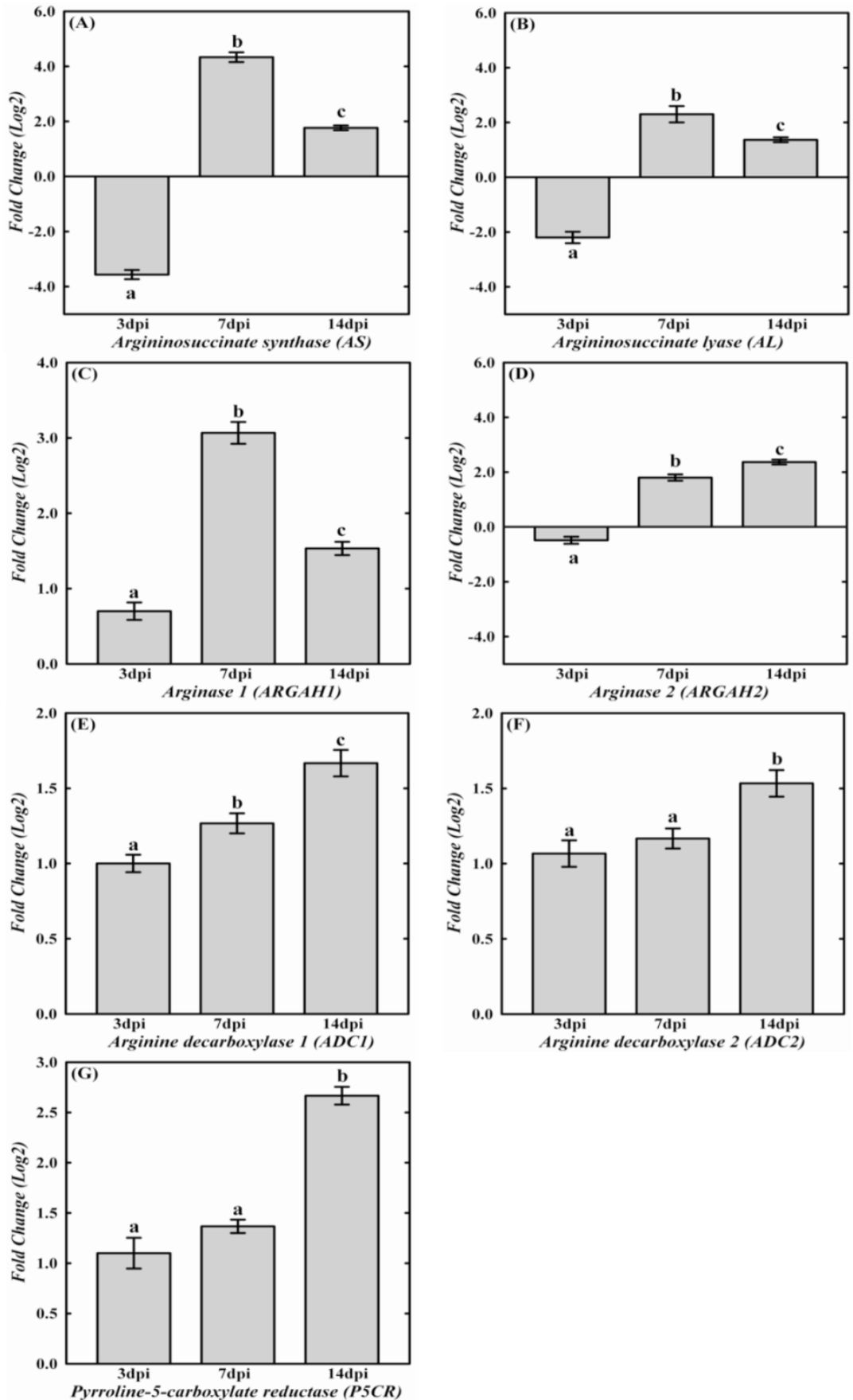

Figure 3. Gene expression patterns of A) argininosuccinate synthase $(A S)$, B) argininosuccinate lyase $(A L), \mathrm{C})$ arginase $1(A R G A H 1), \mathrm{D})$ arginase $2(A R G A H 2), \mathrm{E})$ arginine decarboxylase $1(A D C 1) \mathrm{F}$ ) arginine decarboxylase $2(A D C 2)$ and $\mathrm{G})$ pyrroline-5-carboxylate reductase $(P 5 C R)$ in roots of $A$. thaliana colonized by $S$. indica at $3 d p i$, 7 dpi and 14 dpi. Results were obtained using qRT-PCR and fold changes were calculated using $2^{\text {-ddCT }}$ method. Un-colonized roots from the plants of same age were used as control. Values are means $\pm \mathrm{SE}$, $\mathbf{n}=\mathbf{3}$ (biological replicates), different letters indicate significant difference within time points (p<0.05, one-way ANOVA, LSD) 


\section{Discussion}

There are only few studies on arginine cycle regulation in plants $[17,18]$ and little is known about its role in plant-microbe interactions. Arginine metabolism is reported to be modulated e.g. during A. thaliananematode interaction $[9,19]$ and to be involved in plant defense responses antagonizing pathogens by supporting the nitric oxide production [20]. However, its involvement in the interaction between plants and fungal endophytes is still not known. Therefore, this work was conducted to study involvement of genes connected to this pathway during $S$. indica colonization of $A$. thaliana roots. Our data showed significant modulation at gene expression level in colonized roots. For instance, at 3 dpi we observed strong down-regulation of AS, which is the rate limiting enzyme and its decreased activity have direct relation to the amount of produced arginine [21]. Argininosuccinate, the product of AS action, is the immediate precursor of arginine in urea cycle and its conversion to arginine is catalyzed by AL [22]. AL was also strongly down-regulated at $3 \mathrm{dpi}$, which might result in decreased arginine biosynthesis in $S$. indica colonized roots at early colonization phase. Interestingly, reduction of arginine content by silencing the $A S$ and $A L$ results in better growth of pathogens on A. thaliana [9]. The product of AS and AL is arginine, which is an important amino acid not only for plants but also for microbes as an important nitrogen source [23]. For instance, during mycorrhizal symbioses, amino acids are the compounds responsible for the transfer of nitrogen to host plant [24]. Studies on ectomycorrhizal symbioses showed that during the initial stages of development fungi try to assimilate nitrogen by its own nitrate reductase. To accomplish this, the fungus down-regulates the host genes associated with assimilation of nitrogen $[25,26]$. Further, arginine is connected with many amino acid pathways and serves as important raw material for the synthesis and modification of many proteins, polyamine and alkaloids. These compounds have a vital role in many plant metabolic processes [27] and are reported to be involved in abiotic stress responses as well as in plant-pathogen interactions [28]. During the interaction with pathogens, arginine production can be enhanced by the plant in order to produce higher amounts of nitric oxide (NO) [29], which play a key role in many plant defense responses against invading organisms [30]. $S$. indica at early colonization phase suppresses plant defense responses [31, 32]. Therefore, the initial down-regulation of $A S$ and $A L$ gene at $3 \mathrm{dpi}$, that was observed here, might be the strategy of the endophyte to manipulate plant defenses related to nitric oxide production. At later stages, the host defense responses against $S$. indica are attenuated and the relationship becomes mutualistic [32]. Our results show that at 7 and $14 \mathrm{dpi} A S$ and $A L$ are strongly up-regulated, which might suggest that the arginine synthesis during these phases is enhanced to cover growing nitrogen demands of $S$. indica.

Arginine is catabolized to ornithine via enzyme arginase, which is coded by a set of duplicated arginase genes called ARGAHI and $A R G A H 2$. Differential expression of these two genes was found in A. thaliana roots colonized by $S$. indica with $A R G A H 2$ being down-regulated during the initial stage of fungus colonization. In contrast, at later stages both genes were significantly upregulated. Arginase competes with nitric oxide synthase (NOS) for the common substrate arginine [33]. Hence, it can be speculated that at later stages when arginine is abundant, the fungus tries to attenuate the production of nitric oxide by increasing ornithine production. This phenomenon has been studied in animal parasite systems. For instance, trypanosomes, unicellular parasitic flagellate protozoa, are reported to evade host 
NO-mediated defense responses by stimulating the expression of arginase genes [34], which might result in better stress tolerance and regulation of reactive oxygen species [35]. In A. thaliana, arginase genes mediate a cross talk between $\mathrm{NO}$ and polyamine biosynthesis [36]. Here, we show that two important genes in this pathway, arginine decarboxylase $1(A D C 1)$ and arginine decarboxylase 2 (ADC2), are strongly up-regulated upon $S$. indica colonization.

Proline is an important product of arginine catabolism and can be produced from arginine via many reactions. The final reaction catalyzing ornithine to proline is driven by pyrroline-5-carboxylate reductase (P5CR) [37]. As shown here, the gene encoding this enzyme is up-regulated at 7 and 14 dpi. Increased proline production can be beneficial for many plant responses. For instance, it is involved in osmotic stress management and accumulates as important osmolyte during stress conditions [38] and as a result of dehydration [39]. Accumulation of proline can be a result of incompatible plant microbe interactions [40] and can enhance the root growth by increasing the root meristematic zone [41]. Similarly, AMF are known to be triggering increased root growth [42].

\section{Conclusion}

This study demonstrates that $S$. indica triggers sophisticated modulations of the arginine pathway in colonized $A$. thaliana roots on the gene expression level. Genes encoding key enzymes in this pathway such as $A S, A L$ and $A R G A H 2$ show significant down-regulation at early time points, whereas during later stages they are strongly and significantly up-regulated. These alterations are tightly interconnected with specific colonization phases of the fungus and are most probably indispensable for successful colonization and further development of the mutualistic relationship.
Controlled arginine metabolism might not only help $S$. indica to avoid initial plant defense responses but also might improve conditions to sustain its further growth. Whether $S$. indica does this either to cope with NO-mediated plant defenses or to synthesize important metabolites essential for its growth and development should be in focus of further studies.

\section{Authors' contributions}

Conceived and designed the experiments: S Anwar \& K Wieczorek, Performed the experiments: S Anwar, Analysed the data: S Anwar, Contributed materials/ analysis/ tools: K Wieczorek, Wrote the paper: S Anwar \& K Wieczorek.

\section{Acknowledgment}

We acknowledge the Higher Education Commission (HEC) of Pakistan for funding the work. Help and support from Dr. Holger Bohlmann (BOKU Wien) is also acknowledged.

\section{References}

1. Dawson CJ \& Hilton J (2011). Fertilizer availability in a resource-limited world: Production and recycling of nitrogen and phosphorus. Food Policy 36(1): S14-S22.

2. Newman EI \& Reddell P (1987). The distribution of mycorrhizas among families of vascular plants. New Phytol 106(4): 745751.

3. Azcón-Aguilar C \& Barea JM (1997). Arbuscular mycorrhizas and biological control of soil-borne plant pathogens - an overview of the mechanisms involved. Mycorrhiza 6(6):457-464.

4. Borowicz VA (2001). Do arbuscular mycorrhizal fungi alter plant-pathogen relations? Ecology 82(11): 3057-3068.

5. Clark RB \& Zeto SK (2000). Mineral acquisition by arbuscular mycorrhizal plants, J Plant Nutr 23(7): 867-902.

6. Jacobs S, Zechmann B, Molitor A, Trujillo M, Petutschnig E, Lipka, V, Kogel KH \& Schäfer P (2011). Broad-spectrum suppression of innate immunity is required for colonization of Arabidopsis roots by the fungus Piriformospora indica. Plant Physiol 156(2): 726-740. 
7. Varma A, Savita V, Sudha, Sahay N, Butehorn B \& Franken P (1999). Piriformospora indica, a cultivable plantgrowth-promoting root endophyte. Appl Environ Microbiol 65(6): 2741-2744.

8. Waller F, Mukherjee K, Deshmukh SD, Achatz B, Sharma M, Schafer P \& Kogel KH (2008). Systemic and local modulation of plant responses by Piriformospora indica and related Sebacinales species. J Plant Physiol 165(1): 60-70.

9. Anwar S, Inselsbacher E, Grundler FMW \& Hofmann J (2015). Arginine metabolism of Arabidopsis thaliana is modulated by Heterodera schachtii infection, Nematology 17(9):1027-1043.

10. Anwar S, Wieczorek $K$ \& Inselsbacher $E$ (2018). Analysis of Arabidopsis amino acid metabolism in response to Heterodera schachtii infection. Pakistan Journal of Nematology 36(2): 131-150.

11. Gobert AP, Daulouede S, Lepoivre M, Boucher JL, Bouteille B, Buguet A, Cespuglio R, Veyret B, \& Vincendeau P (2000). L-Arginine availability modulates local nitric oxide production and parasite killing in experimental trypanosomiasis. Infect Immun 68(8): 4653-4657.

12. Curtis MD \& Grossniklaus U (2003). A Gateway Cloning Vector Set for HighThroughput Functional Analysis of Genes in Planta. Plant Physiol 133(2): 462-469.

13. Cseke LJ, Cseke SB \& Podila GK (2007). High efficiency poplar transformation. Plant Cell Rep 26(9):1529-1538.

14. Clough SJ \& Bent AF (1998). Floral dip: a simplified method for Agrobacteriummediated transformation of Arabidopsis thaliana. Plant J 16(6): 735-743.

15. Brownfield DL, Todd CD \& Deyholos MK (2008). Analysis of Arabidopsis arginase gene transcription patterns indicates specific biological functions for recently diverged paralogs. Plant Mol Biol 67(4):429-440.

16. Livak, KJ \& Schmittgen, TD (2001). Analysis of relative gene expression data using real-time quantitative PCR and the $2^{-}$ ${ }^{\text {DDCt }}$ Method. Methods 25(4): 402-408.

17. Shargool D, Jain JC \& McKay G (1988). Ornithine biosynthesis, and arginine biosynthesis and degradation in plant cells. Phytochemistry 27(6): 1571-1574.

18. Slocum RD (2005). Genes, enzymes and regulation of arginine biosynthesis in plants. Plant Physiol Biochem 43(8): 729-745.

19. Hofmann J, El Ashry AEN, Anwar S, Erban A, Kopka J \& Grundler FMW (2010). Metabolic profiling reveals local and systemic responses of host plants to nematode parasitism. Plant $J$ 62(6): 10581071.

20. Gobert AP, Daulouede S, Lepoivre M, Boucher JL, Bouteille B, Buguet A, Cespuglio R, Veyret B \& Vincendeau P (2000). L-Arginine availability modulates local nitric oxide production and parasite killing in experimental trypanosomiasis. Infect Immun 68(8): 4653-4657.

21. Haines RJ, Pendleton LC \& Eichler DC (2011). Argininosuccinate synthase: at the center of arginine metabolism. Int J Biochem Mol Biol 2(1): 8-23.

22. Tischner R, Galli M, Heimer YM, Bielefeld S, Okamoto M, Mack A \& Crawford NM (2007). Interference with the citrullinebased nitric oxide synthase assay by argininosuccinate lyase activity in Arabidopsis extracts. FEBS J 274(16): 42384245 .

23. Micallef BJ \& Shelp BJ (1989). Arginine metabolism in developing soybean cotyledons II. Biosynthesis. Plant Physiol 90(2): 631-634.

24. Hildebrandt U, Schmelzer E \& Bothe H (2002). Expression of nitrate transporter genes in tomato colonized by an arbuscular mycorrhizal fungus. Physiol Plant 115(1): 125-136.

25. Kaldorf M, Schmelzer E \& Bothe H (1998). Expression of maize and fungal nitrate reductase genes in arbuscular mycorrhiza. Mol Plant Microbe Interact 11(6): 439-448.

26. Guescini M, Pierleoni R, Palma F, Zeppa S, Vallorani L, Potenza L, Sacconi C, Giomaro G \& Stocchi V (2003). Characterization of the Tuber borchii nitrate reductase gene and its role in ectomycorrhizae. Mol Genet Genomics 269(6): 807-816.

27. Thomas T \& Thomas TJ (2001). Polyamines in cell growth and cell death: Molecular 
mechanisms and therapeutic applications. Cell Mol Life Sci 58(2): 244-258.

28. Kuznetsov V, Radyukina NL \& Shevyakova NI (2006). Polyamines and stress: Biological role, metabolism, and regulation. Russ $J$ Plant Physiol 53(5): 583-604.

29. Corpas FJ, Palma JM, del Rio LA \& Barroso JB (2009). Evidence supporting the existence of L-arginine-dependent nitric oxide synthase activity in plants. New Phytol 184(1): 9-14.

30. Delledonne M, Xia Y, Dixon RA \& Lamb C (1998). Nitric oxide functions as a signal in plant disease resistance. Nature 394(6693): 585-588.

31. Jacobs S, Zechmann B, Molitor A, Trujillo M, Petutschnig E, Lipka V, Kogel KH \& Schäfer P (2011). Broad-spectrum suppression of innate immunity is required for colonization of Arabidopsis roots by the fungus Piriformospora indica. Plant Physiol 156(2): 726-740.

32. Vahabi K, Sherameti I, Bakshi M, Mrozinska A, Ludwig A, Reichelt M \& Oelmüller R (2015). The interaction of Arabidopsis with Piriformospora indica shifts from initial transient stress induced by fungus-released chemical mediators to a mutualistic interaction after physical contact of the two symbionts. BMC Plant Biol 15: 58.

33. Flores $\mathrm{T}$, Todd $\mathrm{CD}$, Tovar-Mendez $\mathrm{A}$, Dhanoa PK, Correa-Aragunde N, Hoyos ME, Brownfield DM, Mullen RT, Lamattina L \& Polacco JC (2008). Arginase-negative mutants of Arabidopsis exhibit increased nitric oxide signaling in root development. Plant Physiol 147(4): 1936-1946.

34. Duleu S, Vincendeau P, Courtois P, Semballa S, Lagroye I, Daulouède $S$, Boucher JL, Wilson KT, Veyret B \& Gobert AP (2004). Mouse strain susceptibility to trypanosome infection: an arginase- dependent effect. J Immunol 172(10): 62986303.

35. Shi H, Ye T, Chen F, Cheng Z, Wang Y, Yang P, Zhang Y \& Chan Z (2013). Manipulation of arginase expression modulates abiotic stress tolerance in Arabidopsis: effect on arginine metabolism and ROS accumulation. J Exp Bot 64(5): 1367-1379.

36. Shi HT \& Chan Z L (2013). In vivo role of Arabidopsis arginase in arginine metabolism and abiotic stress response. Plant signal behave 8(5): e24138.

37. Kenklies J, Ziehn R, Fritsche K, Pich A \& Andreesen, JR (1999). Proline biosynthesis from L-ornithine in Clostridium sticklandii: purification of Delta 1-pyrroline-5carboxylate reductase, and sequence and expression of the encoding gene. Microbiol 145(4): 819-826.

38. Verbruggen N \& Hermans C (2008). Proline accumulation in plants: a review. Amino Acids 35(4): 753-759.

39. Verslues PE, Agarwal M, Katiyar-Agarwal S, Zhu J \& Zhu JK (2006). Methods and concepts in quantifying resistance to drought, salt and freezing, abiotic stresses that affect plant water status. Plant J 45(4): 523-539.

40. Fabro G, Kovacs I, Pavet V, Szabados L \& Alvarez ME (2004). Proline accumulation and AtP5CS2 gene activation are induced by plant-pathogen incompatible interactions in Arabidopsis. Mol Plant Microbe Interact 17(4): 343-350.

41. Biancucci M, Mattioli R, Moubayidin L, Sabatini S, Costantino $P$ \& Trovato $M$ (2015). Proline affects the size of the root meristematic zone in Arabidopsis. $B M C$ Plant Biol 15: 263.

42. Marschener H (1998). Role of root growth, arbuscular mycorrhiza, and root exudates for the efficiency in nutrient acquisition. Field Crops Res 56(1-2): 203-207. 